\title{
Sensitization with atypical mycobacteria is a potent risk factor for cross-reaction with the delayed type hypersensitivity assay in mice
}

This article was published in the following Dove Press journal:

Pathology and Laboratory Medicine International

14 July 2010

Number of times this article has been viewed

\author{
Eduardo Martins de Sousa' \\ Fernando Bonfim de \\ Bortoli' \\ Bruna Daniella de Souza \\ Silva' \\ Ediane Batista da Silva ${ }^{2}$ \\ Scott M Irwin ${ }^{2}$ \\ Ana Paula Junqueira Kipnis' \\ 'Department of Microbiology, \\ Immunology, Parasitology and \\ Pathology, Institute of Tropical \\ Pathology and Public Health, Federal \\ University of Goias, Goiânia-Go, \\ Brazil; ${ }^{2}$ Department of Pediatrics, \\ University of Texas Medical Branch, \\ Galveston, TX, USA
}

Correspondence: Ana Paula Junqueira Kipnis Rua 325 esquina com Primeira Avenida, Setor Universitário, CEP: 74605-050,

Goiânia-Go, Brazil

Tel +55 I I 6232096174

Fax +55 II 6232096363

Email anapaula@iptsp.ufg.br

\begin{abstract}
Tuberculosis is a disease that infects approximately two billion people worldwide. The current diagnostic test utilizes purified protein derivative (PPD) obtained from Mycobacterium tuberculosis cultures to elicit a host delayed type hypersensitivity reaction to identify infected individuals. This reaction is manifested as an induration at 48 hours following intradermal injection. These experiments demonstrate that in a mouse model, repeated administrations of PPD do not elicit a positive tuberculin skin test (TST). However, prior sensitization to environmental mycobacteria does induce a positive TST when administered via the intraperitoneal or oral route. This work has important implications regarding the specificity of the PPD reagent, disease diagnosis, and environmental mycobacteria.
\end{abstract}

Keywords: tuberculin skin test, environmental mycobacteria, immune response

Tuberculosis (TB) is a chronic disease that affects one third of the world's population. Although these figures are alarming, only $5 \%-10 \%$ of those individuals will progress to active disease..$^{1,2}$ The majority of the individuals are latently infected as defined by the tuberculin skin test (TST). ${ }^{3}$ Purified protein derivative (PPD) is intradermally injected in the forearm of individuals, and after 48 hours, the swelling in response to the crude antigenic cocktail is measured. ${ }^{4}$ The relative response to the test classifies individuals as negative or positive. Generally, TST $>10 \mathrm{~mm}$ is considered a positive reaction in patients. ${ }^{5-7}$ The TST confirms the presence of a delayed hypersensitivity reaction induced by mycobacterial antigens (Mycobacterium tuberculosis and some atypical mycobacteria). However, this reaction does not always prove to be correlated with effective protection against TB. ${ }^{8,9}$

As established in the literature, close household contacts of an active TB patient are more predisposed to develop active disease within a 2-year range than the general population. To identify individuals with increased chances of having active disease, TST is applied at least four times during a 2-year contact follow up. In addition, a two-step TST (to induce a booster phenomenon) has been indicated for pulmonary TB contacts. ${ }^{6,10}$ A bacille Calmette-Guérin (BCG)-vaccinated population can rely on the TST results to identify latently infected individuals. ${ }^{7,11}$

It is well known that epidermal antigen presenting cells such as Langerhans cells present foreign proteins inducing a particular type of immune response (Th2) that is different from that induced by the conjunctive tissue dendritic cells DCs (Th1) when in contact with the same antigens. ${ }^{12}$ In a TB patient contact follow up, PPD can be erroneously injected into the conjunctive tissue, inducing a Th1 immune response 
that could culminate in a delayed-type hypersensitivity reaction capable of eliciting a positive TST.

It is not known whether multiple TSTs or erroneously performed TSTs could elicit a positive skin test reaction and lead to an incorrect diagnosis. Furthermore, the effect of environmental mycobacteria on the TST is not clear. Though the murine model of TB infection does not directly reflect the human disease, it constitutes a valid model to study the mechanisms underling this discussion.

In the present work, we tested whether different PPD administrations could induce a cellular and humoral immune response that would produce a delayed-type hypersensitivity response. Our results show that even in the presence of a PPD-specific immune response in the draining lymph nodes generated by PPD administration, repeated sensitizations do not elicit a positive TST. Prior sensitization with environmental mycobacteria, however, does result in a positive TST, potentially compromising the effectiveness and specificity of the TST for identification of individuals infected with TB.

\section{Materials and methods}

\section{Animals}

Female BALB/c mice at $4-8$ weeks old, weighing 18-22 $\mathrm{g}$ were maintained in our animal facilities under specific pathogen-free conditions.

\section{Animal husbandry}

The animals were maintained under hygienic barrier conditions with free access to food and water. The ambient temperature was maintained between $20^{\circ} \mathrm{C}$ and $24^{\circ} \mathrm{C}$, and relative humidity was maintained between $40 \%$ and $70 \%$ with a 12 -hour light/dark cycle. Mice were allowed to acclimatize for at least 2 days after arrival in the facility in cages with five animals per group. Infected animals were kept in biohazard facilities, housed in cages within a laminar flow safety enclosure. Animals were euthanized by carbon dioxide narcosis. All mice were bred at the Tropical Pathology and Public Health Institute, Federal University of Goias (IPTSP/UFG) and were used under American Veterinary Medical Association (AVMA) protocols.

\section{Bacterial strains}

Strains of M. massiliense were originally isolated from human biopsies in Goiania and were grown at $37^{\circ} \mathrm{C}$ on $7 \mathrm{H} 11$ solid medium supplemented with 10\% OADC (oleic acid, dextrose, catalase) (Difco; Becton-Dickinson, Franklin Lakes, NJ). M. tuberculosis $\mathrm{H} 37 \mathrm{Rv}$ was grown at $37^{\circ} \mathrm{C}$ on $7 \mathrm{H} 11$ solid medium supplemented with $10 \%$ OADC.

\section{Mycobacterial antigens}

Tuberculin PPD RT23 (Statens Serum Institute, Denmark) was used for injection in the hind footpad and for in vitro stimulation assays.

\section{PPD sensitizations}

Mice were sensitized with three applications (1,21, and 90 days) of $100 \mu \mathrm{L}$ of PPD RT23 via the intradermal (id), subcutaneous (sc), or epidermal (ep) route. Epidermal sensitizations were performed by abrading the stratum corneum and applying PPD directly to the epidermis. Control mice were treated with saline. two days after the last sensitization, lymph node cells were isolated and flow cytometry was performed. Serum was analyzed for the presence of antigen-reactive IgG1 and IgG2a.

\section{Lymphocyte isolation}

Five mice per group were euthanized and the draining popliteal lymph nodes from each mouse were isolated and processed individually. Single-cell suspensions were prepared by pressing the lymph node cells through a cell strainer (BD Falcon; Becton Dickinson) with the help of a sterile syringe plunger. Cells were collected in complete RPMI 1640 media (Gibco, Carlsbad, CA) supplemented with 10\% heat-inactivated fetal calf serum (Gibco), $20 \mathrm{mM}$ HEPES, $0.05 \mathrm{mM}$ mercaptoethanol, $2 \mathrm{mM}$ L-glutamine, $1 \mathrm{mM}$ sodium pyruvate, $1 \%$ nonessential amino acids (Sigma, St. Louis, $\mathrm{MO}$ ), and antibiotics (penicillin, streptomycin). The total number of cells obtained from each organ was calculated. Cells were resuspended at $1 \times 10^{6}$ cells $/ \mathrm{mL}$, and $100 \mu \mathrm{L}$ of suspension was deposited in each well of a 96-well plate and stimulated with PPD $(10 \mu \mathrm{g} / \mathrm{mL})$ or ConA $(1 \mu \mathrm{g} / \mathrm{mL})$ as a positive control.

\section{Enzyme-linked immunosorbent assay (ELISA)}

90 days after all 3 PPD sensitizations, blood was collected through the retrorbital plexus, and serum was obtained by centrifugation at $1500 \times g$ for 10 minutes. PPD RT23 was coated $(10 \mu \mathrm{g} / \mathrm{mL})$ in $0.06 \mathrm{M}$ carbonate/bicarbonate buffer $\mathrm{pH}$ 9.6 onto 96 -well (Nunc ${ }^{\circledR}$, Rochester, NY) plates by overnight incubation at $4{ }^{\circ} \mathrm{C}$. After overnight incubation, the plates were blocked with $5 \%(\mathrm{w} / \mathrm{v})$ skim milk in phosphate-buffered saline (PBS) $-0.05 \%$ tween 20 for 2 hours at $37^{\circ} \mathrm{C}$ and further washed with the blocking solution. Serum samples were diluted 1:100 in $1 \%(\mathrm{w} / \mathrm{v})$ skim milk in PBS- $0.05 \%$ tween 20 and incubated for 1 hour at $37^{\circ} \mathrm{C}$. After 6 washes with PBS- $0.05 \%$ tween $20,50 \mu \mathrm{L}$ of the secondary antibody biotin-conjugated goat anti-mouse IgG2a and biotin-conjugated goat anti-mouse IgG1 antibodies 
(BD, Pharmingen, San Jose, CA) diluted 1:5000 in 1\% (w/v) skim milk in PBS-0.05\% tween 20 was added and incubated for 1 hour at $37^{\circ} \mathrm{C}$. After six washes with PBS- $0.05 \%$ tween 20, $50 \mu \mathrm{L}$ of Avidin-HRP (BD Pharmingen) diluted 1:1000 in $1 \%(\mathrm{w} / \mathrm{v})$ skim milk in PBS-0.05\% tween 20 was added and incubated for 1 hour at $37^{\circ} \mathrm{C}$. After six washes, the colorimetric reaction was developed with the substrate solution composed of citrate buffer $\mathrm{pH} 5.0,5 \mu \mathrm{g} / \mathrm{mL}$ OPD (orthophenylenediamine) (Sigma) and $20 \mu \mathrm{L} \mathrm{H}_{2} \mathrm{O}_{2}(30 \mathrm{~V})$. Absorbance values were obtained with a spectrometer Multiskan Plus at $595 \mathrm{~nm}$, and blanks were subtracted for each sample. The diluted test sera were evaluated in triplicate, and the average absorbance at $595 \mathrm{~nm}$ was expressed in optical density units. The ELISA was optimized using control sera from normal healthy mice, and internal controls of the reaction evaluating mice sera and conjugated antibodies reaction to the skim milk. Also, all dilutions used were optimized before the standard protocol was adopted.

\section{Flow cytometric analysis}

For flow cytometric analysis the lymph node cells were treated with Golgi Stop Solution (monensin) (BD Pharmingen), and after 6 hours of further incubation at $37^{\circ} \mathrm{C}$ on a $5 \% \mathrm{CO}_{2}$ atmosphere, cells were harvested for the test. To perform surface and intracellular staining, the cells were transferred to a 96-well plate and treated with PBS/Azide $0,05 \%$ for 20 minutes. After centrifugation ( $3000 \mathrm{rpm}$ for 10 minutes), the cells were stained at $4^{\circ} \mathrm{C}$ for 18 minutes with surface marker Abs (anti-CD5-FITC). The plates were washed twice with PBS/Azide $0.05 \%$ and treated with PermFix (BD Pharmingen) for 18 minutes. For intracellular staining, cells were permeabilized with Perm Wash buffer (BD Pharmingen) and incubated at $4^{\circ} \mathrm{C}$ for 18 minutes with specific antibodies anti-IFN- $\gamma$-Biotin, Avidin-PerCP, and IL-4-PE. After washes, the samples were immediately acquired on FACSCalibur (Becton Dickinson) in Hospital Araújo Jorge (Goiás, Brazil). All monoclonal antibodies used in here were from BD Pharmingen. A minimum of 50,000 events was acquired per sample. The data analysis was performed with FACSDiva software (BD Bioscience; Becton Dickinson). After identification of the lymphocyte gate according to the cell size and granularity, CD5 positive cells were gated and analyzed for the expression of IFN- $\gamma$ and IL-4.

\section{Experimental infection}

Mice were infected via the intravenous, subcutaneous route with $0.1 \mathrm{~mL}$ of $M$. massiliense (MA) suspension containing $1 \times 10^{6} \mathrm{CFU}$, or via the oral route with 0.1 or $0.2 \mathrm{~mL}$ of
MA suspension containing $1 \times 10^{6}$ colony-forming units (CFU) (vo, $2 \times$ vo). Infected animals were kept in biohazard facilities, housed in cages with 5 animals per group within a laminar flow safety enclosure. A group composed of intravenous $M$. tuberculosis-infected mice (H37rv strain $\left(1 \times 10^{6}\right.$ $\mathrm{CFU}$ ) was used as a positive control and in order to confirm the infection, at specific time post infection, the spleen and liver homogenates were submitted to serial five-fold dilutions in PBS and were plated onto 7H11 agar plates, and CFU were determined. Four to six weeks after infection with environmental mycobacteria or $M$. tuberculosis, mice were challenged with $0.1 \mathrm{~mL}$ of PPD RT23 (2 UT) (Statens Serum Institut, Copenhagen, Denmark) into the right hind footpad, and the increase in footpad swelling was compared with the left hind footpad of the same mouse injected with saline.

\section{Delayed type hypersensitivity assay}

Delayed type hypersensitivity (DTH) was assayed by cutaneous sensitivity in the footpad. After injection of $100 \mu \mathrm{L}$ of PPD RT23 (2 UT) (Statens Serum Institut) into the hind footpads of mice, swelling was measured with a dial-gauge caliper (Newman Tools Inc., Hartford, CT) at 48 and 72 hours. The minimum measurable increment was $0.1 \mathrm{~mm}$. The footpad swelling was expressed as the difference between the swelling of the treated footpad and the mean of the swelling induced by an injection of PBS. The locations of the skin tests were randomized and two independent readers read the diameters of the swelling after 48 and 72 hours in a blinded manner. The variation between the two readings was always less than $10 \%$, and the results were expressed as the mean of the two readings.

\section{Statistical analysis}

Fisher's exact test and Student's $t$-test were used to analyze the significance of quantitative data; $P$ values less than 0.05 were considered significant.

\section{Results Characterization of T cells involved in the response to PPD after TST}

PPD is a M. tuberculosis culture filtrate that is not completely pure. PPD mixture may contain mycobacteria cell wall components that could act as adjuvant inducing specific immune response to its proteins. Then, repeated TST might induce specific Th1 immune response to PPD proteins that could culminate with a positive TST. In order to evaluate if repeated TST injections and different routes would induce a specific TST response, mice were TST sensitized, and the 
$\mathrm{T}$ cells elicited on the draining lymph node were analyzed by flow cytometry. Figure 1 shows that when sensitized subcutaneously, the percentage of $\mathrm{CD} 5^{+} \mathrm{IL}-4^{+}$lymphocytes analyzed ex vivo was higher $(4.0 \pm 1.2)$ when compared with other groups (id $=1.4 \pm 1.0$; ep $=2.4 \pm 0.3)$ and the saline injected group $(2.2 \pm 0.4)(P<0.05)$. No differences were observed in the number of $\mathrm{CD} 5^{+} \mathrm{IFN}-\gamma^{+}$cells examined ex vivo (Figure 1).

When these cells were cultured and stimulated with PPD, we observed that the intradermal route of sensitization resulted in the largest percentage of $\mathrm{CD}^{+}$cells producing either $\mathrm{IL}_{-4}{ }^{+}(\mathrm{id}=1.7 \pm 0.1 ; \mathrm{sc}=0.9 \pm 0.04$; ep $=0.9 \pm 0.03$; saline $=0.8 \pm 0.3)(P<0.03)$ or IFN- $\gamma^{+}(\mathrm{id}=1.9 \pm 0.1 ; \mathrm{sc}=1.1 \pm 0.3$; ep $=0.9 \pm 0.4$; saline $=1.1 \pm 0.1)$ when compared with the other groups $(P<0.03)$ (Figure 2$)$. This result showed that PPD injections by intradermal route induce a specific immune response.
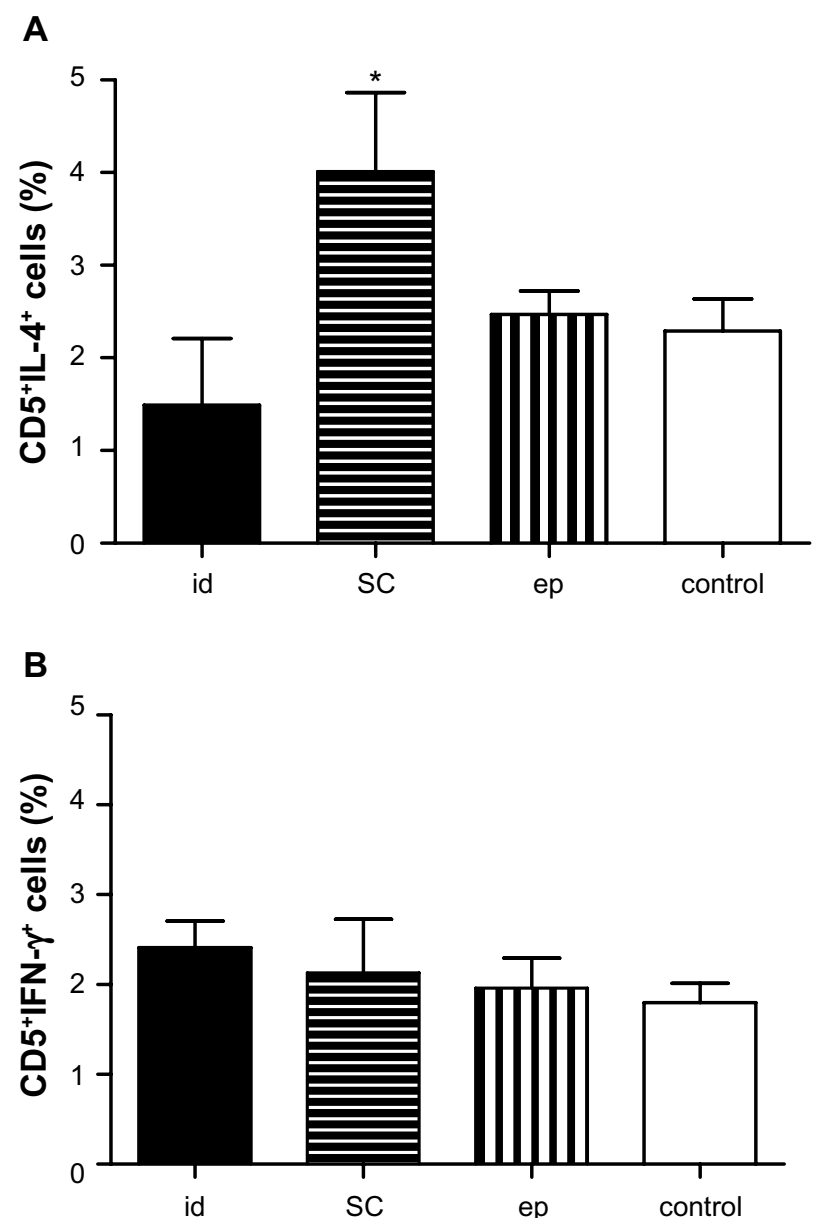

Figure I Specificity of $\mathrm{T}$ cells involved in response to purified protein derivative (PPD) stimulation. Cells were collected from the draining lymph nodes after 3 subsequent PPD stimuli. A) Percentage of TCD5 $5^{+} \mathrm{IL}-4^{+}$cells from mice stimulated with PPD intradermally (id), subcutaneously (sc), and epidermally (ep). B) Percentage of TCD5 ${ }^{+}$IFN- $\gamma^{+}$cells. Control group were injected with saline. The results are from a typical ex vivo experiment and represent the mean $\pm \operatorname{SEM}(n=5)$.

Note: *denotes $P<0.05$.
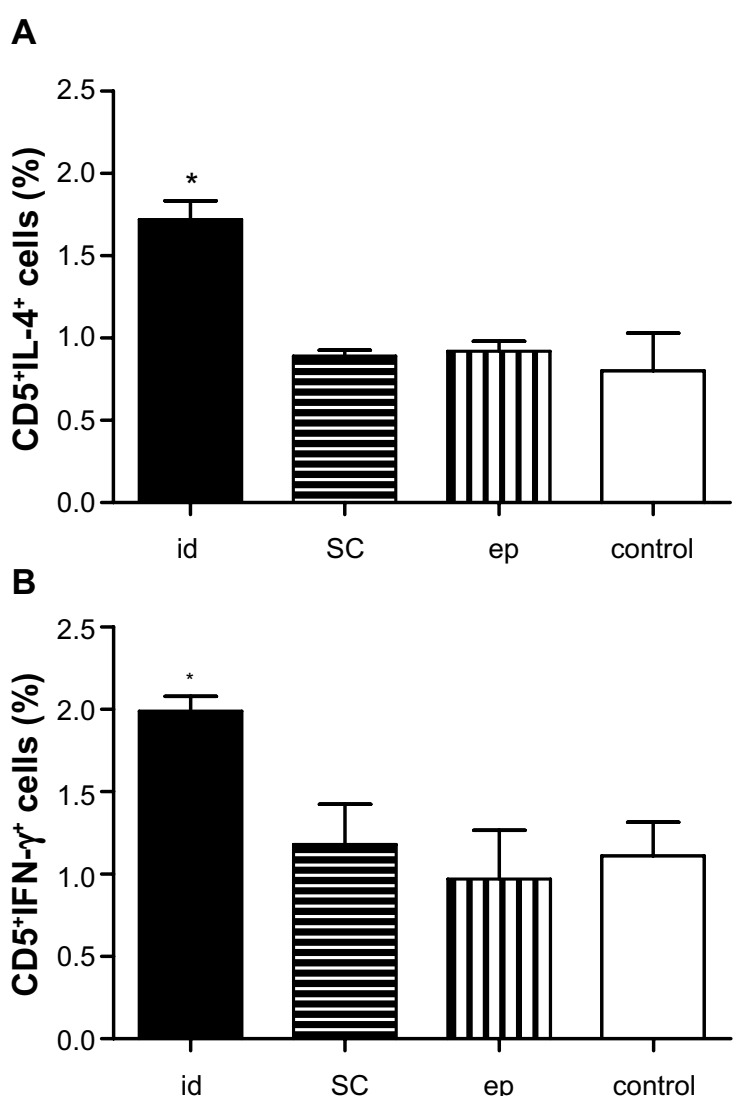

Figure 2 Specificity of $T$ cells involved in response to purified protein derivative (PPD) stimulation. Cells were collected from the draining lymph nodes after 3 subsequent PPD stimuli and were re-stimulated in vitro with PPD. A) Percentage of TCD5 ${ }^{+}$IL-4 ${ }^{+}$cells from mice stimulated with PPD intradermally (id), subcutaneously (sc), and epidermally (ep). B) Percentage of TCD5 ${ }^{+} \mathrm{IFN}-\gamma^{+}$cells from the same groups. Control animals were injected with saline. The results represent the mean $\pm \operatorname{SEM}(n=5)$.

Note: *denotes $P<0.05$.

\section{Antibody response to PPD sensitization}

In order to evaluate if a specific humoral immune response was elicited against PPD after sensitization, serum levels of IgG1 and IgG2a was determined by the ELISA. No PPD-specific IgG1 antibodies were detected at levels exceeding those present in the sera of control mice. In contrast, it was observed that PPD-specific IgG2a was produced in mice sensitized to PPD via the intradermal $(0.19 \pm 0.009)$ and epidermal $(0.17 \pm 0.002)$ routes as compared with control mice $(0.15 \pm 0.002)$ but not with subcutaneous group $(0.18 \pm 0.07)$ $(P<0.03)$ (Figure 3).

\section{DTH induction after different routes of PPD sensitization}

In order to examine whether consecutive sensitizations with PPD would lead to a positive TST, mice were sensitized repeatedly through different routes with PPD and were subjected to TST. It was observed that previous exposure to mycobacterial antigens such as PPD did not lead to a positive TST in any 

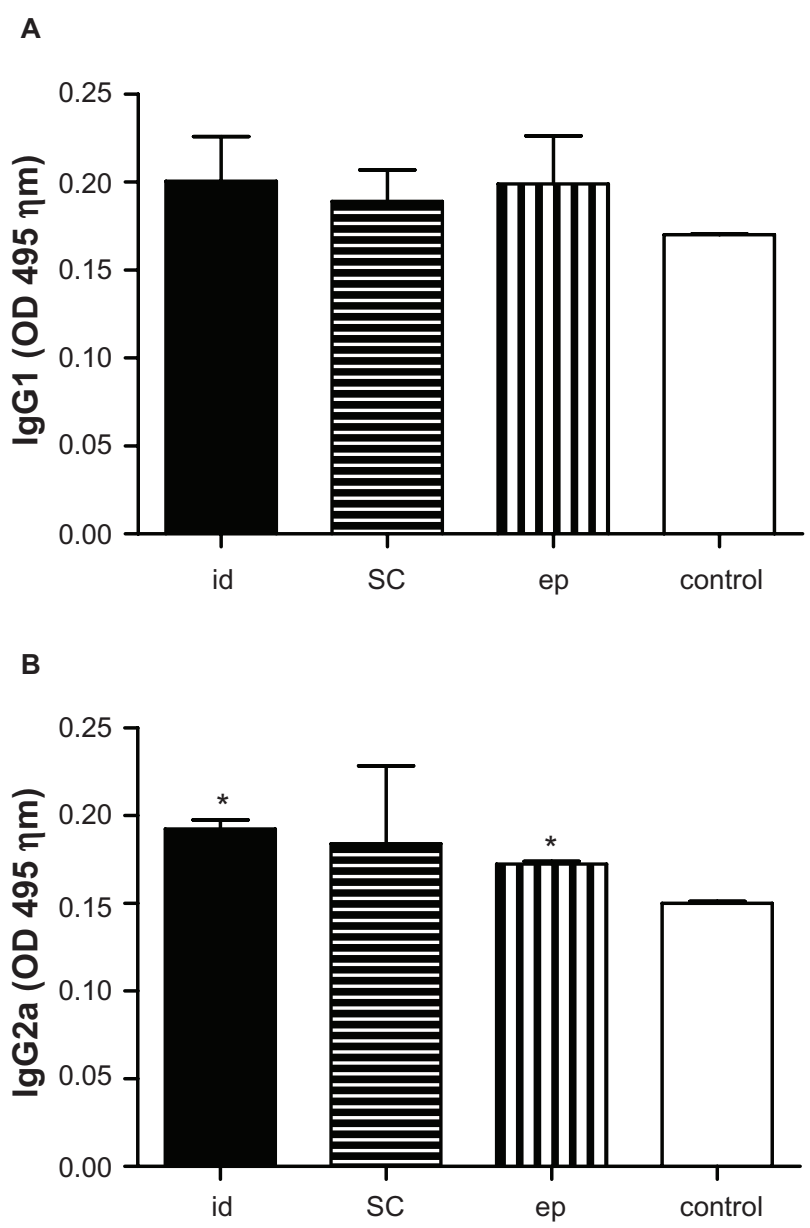

Figure 3 Specific antibodies response against purified protein derivative (PPD). A) IgGI serum level in mice sensitized with PPD intradermally (id), subcutaneously (sc), and epidermally (ep). B) IgG2a serum level. The results represent the absorbance of the tests, and mean \pm SEM is showed $(n=5)$.

Note: *denotes $P<0.05$.

group analyzed (data not shown). Together, these results suggest that although able to induce a specific response to PPD, this fact was not sufficient to induce a DTH in this model.

\section{Relationship between DTH and infection with atypical mycobacteria}

$\mathrm{TB}$ endemic countries commonly present a rich ecological niche for environmental mycobacteria. Environmental mycobacteria colonize tap water and eventually can orally immunize and affect the TST performance. To assess the relationship between the result of DTH and cross-reactivity with environmental mycobacteria, we tested the TST reaction in the footpads after infection with $M$. massiliense. We demonstrated that different routes of $M$. massiliense infection induce a DTH response. Mice that were infected via the intraperitoneal (ip) $(10 \pm 1.6)$ and oral (vo $=6 \pm 1.2$; $2 \times$ vo $=20 \pm 0.8$ ) routes with atypical mycobacteria showed greater hypersensitivity reactions than mice intravenously (iv) infected $(2 \pm 1.3, P<0.001)$. M. tuberculosis infection (Mtb) induced the highest DTH response ( $30 \pm 0.8, P<0.001)$. It was also observed that 72 hours after injection with PPD, the hypersensitivity reaction was smaller (ip $=8 \pm 1.6$; vo $=2 \pm 0.5 ; 2 \times$ vo $=18 \pm 0.8 ;$ iv $=2 \pm 0.6 ; \mathrm{Mtb}=24 \pm 1.3$ ) $(P<0.001)$ than that observed at 48 hours (Figure 4$)$.

\section{Discussion}

One of the major questions surrounding the use of the TST as a diagnostic tool is whether repeated administrations of PPD can ultimately result in a positive TST test. In a mouse model, we demonstrated that PPD administration does in
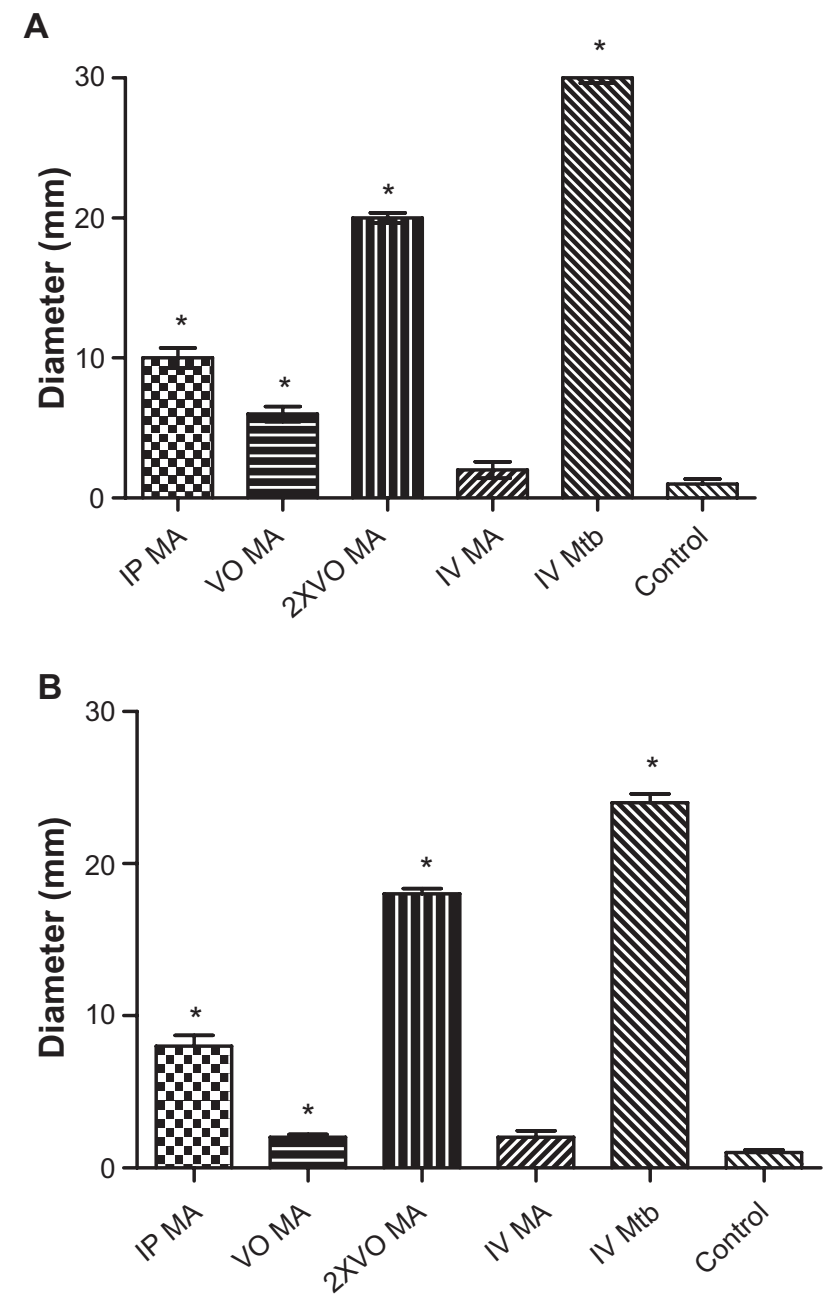

Figure 4 Relation between exposure to environmental mycobacteria and delayed type hypersensitivity (DTH) to purified protein derivative (PPD). BALB/c mice $(n=5)$ were infected via intraperitoneal (ip), oral (vo), intravenous (iv) with Mycobacterium massiliense (MA). Control animals were infected with M. tuberculosis (H37Rv) (Mtb) or saline (Control). 30 days after the infection, the animals were tested with 2UT $(0.1 \mathrm{~mL})$ of PPD. The DTH reaction 48 hours $(\mathbf{A})$ and in 72 hours $(\mathbf{B})$ was measured with a dial gauge caliper. The results represent the mean + SEM of the difference between the swelling of the footpads injected with PPD and control injections of PBS of each mouse.

Note: *denotes $P<0.05$. 
fact induce a specific Th1 or Th2 immune response in the draining lymph nodes (Figure 1); however, this immune response does not elicit a positive TST, even after multiple sensitizations.

Various studies showed that M. tuberculosis and BCG are potent stimulators of DCs. ${ }^{13}$ Inaba et al ${ }^{14}$ demonstrated that DCs after in vitro phagocytosis of BCG and following injection into mouse footpads migrate to the lymph nodes and spleen. Consequently, DCs can present PPD antigens and therefore activate antigen-specific $T$ cells capable of producing cytokines such as IFN- $\gamma$. In our study, PPD administered subcutaneously and applied to the epidermis in the absence of the stratum corneum induced recruitment of antigenpresenting cells (APC), probably Langerhans Cells (LCs), which, migrate to the draining LN and preferentially initiated a Th2 response. ${ }^{15}$ This fact explains the greater humoral immune response in these groups.

In these experiments, higher IgG2a levels were seen using sensitizations via the intradermal and epidermal routes. This aspect can indicate a Th1-dependant immune response that was stimulated by PPD. Although, PPD also increases activity of regulatory T cells and downregulation of the Th17 response. ${ }^{16}$

Here, we demonstrated that previous exposure to PPD does not induce a positive TST reaction; however, atypical mycobacteria can cause cross-reactivity with PPD leading to a positive TST. Atypical mycobacteria are common in tropical environments. Although these atypical mycobacteria are not virulent, research indicates that environmental mycobacteria might be capable of modulating the host's immune status, which provides a possible explanation for the reported failure of BCG vaccine. ${ }^{17,18}$

The outcome of prior exposure with atypical mycobacteria resulted in a positive TST (Figure 4). These observations suggest that prior sensitization with environmental mycobacteria poses a risk of cross-reactivity with the current TST, potentially producing false positive results. This fact can be easily explained because PPD is composed of about 200 antigens shared by $M$. tuberculosis, M. bovis-BCG, ${ }^{19}$ and environmental mycobacteria. ${ }^{20,21}$ This work provides important insights regarding the reliability of repeated usage of PPD for routine TB screening and highlights potential complications that can occur after infection with environmental mycobacteria as the result of the lack of specificity of the PPD-based TST.

\section{Acknowledgments}

The authors thank D Mark Estes, University of Texas Medical Branch for critically reviewing the manuscript. This work was supported by the following grant 479605/2007-6 from Conselho Nacional de Desenvolvimento Científico e Tecnológico (CNPq), Brazil.

\section{Disclosure}

The authors report no conflicts of interest in this work.

\section{References}

1. Dye C, Watt CJ, Bleed DM, Hosseini SM, Raviglione MC. Evolution of tuberculosis control and prospects for reducing tuberculosis incidence, prevalence, and deaths globally. JAMA. 2005;293:2767-2775.

2. Vasconcelos-Junior AC, Araújo-Filho JA, Silva EB, Sousa EM, Kipnis A, Junqueira-Kipnis AP. Limitations of the BCG vaccine and new prophylaxis strategies against human tuberculosis. Einstein. 2009;7:383-389.

3. Nelson K. Tuberculin testing to detect latent tuberculosis in developing countries. Epidemiology. 2007;18:348-349.

4. García-Sancho FMC, García-García L, Jiménez-Corona ME, et al. Is tuberculin skin testing useful to diagnose latent tuberculosis in BCGvaccinated children? Int J Epidemiol. 2006;35:1447-1454.

5. Hizel K, Maral I, Karakus R, Aktas F. The influence of BCG immunization on tuberculin reactivity and booster effect in adults in a country with a high prevalence of tuberculosis. Clin Microbiol Infect. 2004;10:980-983

6. Teixeira EG, Kritski A, Ruffino-Netto A, et al. Two-step tuberculin skin test and booster phenomenon prevalence among Brazilian medical students. Int J Tuberc Lung Dis. 2008;12:1407-1413.

7. Reid JK, Ward H, Marciniuk D, Hudson S, Smith P, Hoeppner V. The effect of neonatal bacille Calmette-Guérin vaccination on purified protein derivative skin test results in Canadian aboriginal children. Chest. 2007;131:1806-1810.

8. Menzies D. What does tuberculin reactivity after bacille CalmetteGuérin vaccination tell us? Clin Infect Dis. 2000;31(3):71-73.

9. Verbon A, Cobelens FG. Indications for, and the significance of, the tuberculin test in the Netherlands. Ned Tijdschr Geneeskd. 2003;147: 539-543.

10. Wu X, Zhang L, Zhang J, Zangh C, Zhu L, Shi Y. Recombinant early secreted antigen target 6 protein as a skin test antigen for the specific detection of Mycobacterium tuberculosis infection. Clin Exp Immunol. 2008;152:81-87.

11. Bozaykut A, Ipek IO, Ozkars MY, Seren LP, Atay E. Effect of BCG vaccine on tuberculin skin tests in 1-6-year-old children. Acta Paediatr. 2002;91:235-238.

12. Miranda A, Amadeu TP, Schueler G, et al. Increased Langerhans cell accumulation after mycobacterial stimuli. Histopathology. 2007; 51:649-656

13. Henderson RA, Watkins SC, Flynn JL. Activation of human dendritic cells following infection with Mycobacterium tuberculosis. J Immunol. 1997;159:635-643

14. Inaba K, Inaba M, Naito M, Steinman RM. Dendritic-cell progenitors phagocytose particulates, including bacillus Calmette - Guérin organisms, and sensitize mice to mycobacterial antigens in vivo. J Exp Med. 1993;178:479-488.

15. Callard RE, Harper JI. The skin barrier, atopic dermatitis and allergy: a role of langerhans cells? Trends Immunol. 2007;28:294-298.

16. Babu S, Bhat SQ, Kumar NP, Kumaraswami V, Nutman TB. Regulatory T cells modulate Th17 responses in patients with positive tuberculin skin test results. $J$ Infect Dis. 2009;69:359-369.

17. Palmer CE, Long MW. 1966. Effects of infection with atypical mycobacteria on BCG vaccination and tuberculosis. Am Rev Respir Dis. 1966;94:553-568.

18. Shield MJ, Stanford JL, Rook GAW. The reason for the reduction of the protective efficacy of BCG in Burma. Int J Leprosy. 1979;47: 319-320. 
19. Al-Orainey IO. Diagnosis of latent tuberculosis: can we do better? Ann Thorac Med. 2009;4:5-9.

20. Farhat M, Greenaway C, Pai M, Menzies D. False-positive tuberculin skin tests: what is the absolute effect of BCG and non-tuberculous mycobacteria? Int J Tuberc Lung Dis. 2006;13:1192-1204.
21. de Kantor IN, Ritacco V. Is the tuberculin skin test still suitable to diagnose tuberculosis infection? Medicina. 2009;69:359-369.

\section{Publish your work in this journal}

Pathology and Laboratory Medicine International is a peer-reviewed, open access journal focusing on innovative basic research and translational research related to pathology or human disease. The journal includes original research, updates, case reports, reviews and commentaries on current controversies. The Academic Sponsor of this journal is the Chinese American Pathology Association (CAPA). The manuscript management system is completely online and includes a very quick and fair peer-review system. Visit http://www.dovepress.com/testimonials.php to read real quotes from published authors.

Submit your manuscript here: http://www.dovepress.com/pathology-and-laboratory-medicine-international-journal 